self-complacent young ladies like to be amused, while at the same time flattering themselves that they are doing a noble work. Tre could well dispense with these; but for such nurses as those at Sedan we cannot be too thankful.

The organisation, or, more correctly speaking, the want of organisation, of the English National Society, is a point about which we should like to have said a few words; but we have already expressed our criticisms so freely, and have already taken up so much space, that we must leare this subject untouched.

Hanley, Staffurdshire, October, $18 \% 0$.

\section{TWO CASES OF}

\section{SUDDEN DEATH FROM UNUSUAL CAUSES.}

BY J. WILKIE BURMAN, M.B.,

ASSISTANT MEDICAL OFEYCER TO THE DEYON COLNTY LUXATIC ASYLUM, EYMINSTER.

I VENTURE to publish details of the two following cases, because $I$ think they will prove not uninteresting to most members of the profession on account of their rarity, and because it is due to the interests of pathology that such cases should be placed on authentic record, and not passed by unheeded.

CASE 1. Rupture of Abscess of Cerebellum, cansing Compression of the Medulla Oblongata and Sudden Death.-William W- - fellmonger, aged thirty-eight. When admitted, on April 29th, 1868, was found to be suffering from simple dementia. His history, from admission up till about a week before his death, is as follows:- He was always harmless and free from excitement; he generally moped about, and seldom or never employed himself usefully; he was much given to turning "head over heels" in the airing courts and ward, and even in bed he could not resist this peculiar propensity. He was also in the habit of jerking his head backwards and to the right. On Nov. 21st, 1869, about five days before his death, he was observed sitting on seat in his ward complaining of a violent pain in the head. The pain seemed to come on in paroxysms, for he frequently put his hands to his head, and screamed, groaned, or stamped his feet on the floor. It may be here observed that at this time, as well as up to the time of his death, the patient took his food well, and exhibited no symptoms of constitutional disturbance; and, as no further information could be obtained from him on account of his demented condition, he was simply ordered to be kept under observation. From Nov. 21st to 26 th he was, on several occasions, noticed to be in the condition above described; and, for two or three nights before his death, he frequently awoke the other patients who slept in the same dormitory as himself by his screaming, and by his getting out of bed and turning head over heels. On the night preceding the dny of his death he was unusually restless and noisy in this especial manner. I may here state that it was not unusual for the patient to have two or three turns over in bed before going to sleep; but it was extraordinary for him to get out of bed to do so, or to scream so as to awaken the other patients.

On the morning of Nov. 26th, at "getting-up" time, the patient asked the attendant in charge of his ward to allow him to remain in bed, as he did "not feel well," and his request was granted. About an hour and a balf afterwards the attendant brought patient his breakfast, which consisted of a basin of flour-and-meal gruel with a piece of bread; and, leaving him to eat it, went elsewhere. On the return of the attendant, about twenty minutes afterwards, to take away the basin, patient was found dead, being slightly livid, and a little froth existing about the lips. The occurrence was immediately reported to the medical officers, who saw him soon afterwards and made the following observations:-Patient was quite dead, and there was little or no lividity of the face or lips; all the gruel had been consumed as well as balf of the bread, the other half lving on the bed near his right hand, which was outside the bedclothes; the left hand was under the bedclothes, which were undisturbed; and the patient was lying on his back. There was no bolus of food in the mouth or at the top of the pharynx, and, as the patient was not in any way paralysed, there was no reason to believe that he had died from accidental choking.
Sectio cadaveris. - The head and thorax were alone examined. The lungs and heart were found to be quite healthy; the heart was flaccid.-Heid: The whole of the cerebrum and its membranes preserted a healthy appearance to the naked eye. On removing the brain in toto from the skull, after the usual manner, a quantity of greenishyellow pus was observed to issue from the top of the spinal cavity and from around the cord at that part. The inferior surface of the left lobe of the cerebellum, which was free from adhesions, was found to be of a brownish-yellow colour, and its substance softened and disintegrated. The affected part of the lobe had the appearance of a pouch containing fluid, and, on shaking it, visible fluctuation was caused. No distinct hole could be made out, but the tip of the finger could be passed through and between the disintegrated fibres into a cavity in the left lobe, which was duly exposed on section, and found to be about an inch and a half in dia. meter, and to be partly filled with a greenish-yellow pus of the same nature as that which bad already been observed to flow by gravitation from the top of the spinal cavity. The abscess was not encysted, and had no lining membrane. The other lobe of the cerebellum was quite healthy, as were also the medulla oblongata, the spinal cord, and their membranes.

CASE 2. Sudden Death from Rupture of the Heart.-Elizabeth D- - on admission, in July, 1862, was sixty-three years of age, and found to be suffering from melancholia. Her history, from admission up till the time of her death, is as follows:- She was always quiet and inoffensive, and gene. rally assisted in the kitchen. She had continued to gain flesh ever since admission, and at the time of her death was very stout. She had become considerably demented during the last year or two of her life. On the evening of the 25th of April, 1870, at bedtime, while undressing, the patient fell down dead. About five minutes after she had dropped down she was seen by the medical officers, and found lying on her back on the floor beside her bed. She was paitly undressed and quite dead; the face, lips, and tongue pre. sented a livid appearance. She had taken her tea, as usual, about an hour and a half before going to bed, and had worked in the kitchen most of the day.

Sectio cadaveris. - The body was very well nourished, and the subcutaneous layer of adipose tissue over the thorax and abdomen varied in thickness from one to two inches.Head: The brain was somewhat softer and more friable than usual, and all the sinuses of its membranes were filled with dark fluid blood. The skull was thicker than usual, and the dura mater adherent to it throughout the greater part of its extent. In all other respeets the brain and its membranes were normal.-Thorax: Un opening the pericardium it was found to be filled with blood, partly coagulated and surrounding the heart as a thick layer. The coaoulum was adherent at some points to the inner surface of the pericardium, which was villous and shaggy from organised lymph. On removing the heart and upper part of the aorta from the pericardium, and clearing away the surrounding coagulum, a rupture of the anterior wall of the left ventricle was observed, about an inch above the, apex and the same distance from the anterior ventricular groove. The external aperture of this rupture was about half an inch in lensth, and its longitudinal axis coincided with the direction of the external layer of muscular fibres. Around the external aperture the substance of the heart was ecchymosed. On opening the left ventricle, it was found to contain clotted blood, and on its inner surface, corresponding to the point of external aperture, the clot was found to be adberent to the ventricular wall and to otber smaller clots extravasated into the muscular substance at that part. On removing the clots, the complete rupture in the ventricular wall was observed, and through the apert ure the little finger could readily be passed. The remaining cavities of the heart contained fluid blood. The heart was larger than usual, and its cavities were dilated, and, when opened and freed from clots, it weighed eighteen ounces. Its substance was pale, fatty, and friable, and it was enveloped in an unusual amount of fat, to which mainly the increase in the weight of the heart was due, for the wails of the ventricles possessed little if any more than ordinary thickness. 'J'here was no aneurism or dilatation of the aurta, and the lungs were healthy.-Abdomen: The liver was fatty and congested, and presented a "nutmeg" appiarance.

Addendum.-These cases, which are mainly of interest 
from a patbological point of riew, call for little remark; but it may be added, with regard to Case 1, that the abscess was "idiopathic" in so far as no cause was ascertained, the patient being otherwise in good bodily health, and never haring had, so far as is known, any blow or injury to the head, either before or after admission. It would be interesting to endeavour to solve the problem as to whether there was any connexion between the patient's habit of turning " head over heels" and jerking his head backwards and to the right, and the lesion of the cerebellum which ended in abscess, did time and space permit; but I would fain leave this in the hands of better physiologists than myself, remarking that, although the insane have many peculiar habits, those of this patient are uncommon, at any rate so far as the experience of this asylum goes. Recollecting the results of Magendie's experiments on the cerebellum, when, by dividing the crus cerebelli on either side, he obtained rutatory and grvatory movements of the animals experimented upon, I cannot but think there may have been some connexion between the disease and the peculiar habit; for the softening and disintegration around the abscess, in this case, affected considerably the crus cerebelli on the diseased side.

Exminster, November, 1870.

\section{PERMANGANATE OF POTASH IN THE TREATMENT OF GONORRHCEA} AND GLEET.

\section{BY THOMAS WARDEN, M.D.}

IN proof of the opinion contained in this paper: I regret that I cannot produce a respectable number of cases to confirm my belief that the diseases mentioned at the head of this article can be cured in about a couple of days. I have delayed putting my small experience of the treatment in print in the hope of getting more evidence as to its utility; but really nowadays it is quite rare to get a case of gonorrhcea to treat. I refer to the Mediterranean station. About the years 1860 to 1863 the cases of gonorrhœa and syphilis were rife in most of the ports; but since that time they have been steadily decreasing, and this is entirely due to the regular inspection in the French and Italian towns and ports. In Turkey and Egypt, where there is, I believe, a nominal supervision, we find syphilis more frequently than gonorrhoa.

During the months of April, May, and June I was doing duty in her Majesty's ship Hibernia at Malta, where disease is at a minimum ; but occasionally sporadic cases of disease make their appearance, where contracted or how imported has never been properly found out. I believe the merchant seamen must be blamed for their introduction, because with the periodical inspection of the men of the Royal Navy it is hardly possible that they should communicate it. I do not know the regulations in the army there, but I believe inspections are held in it also. The disease is easily kept in check in Malta, because the public women are comparatively few compared with the number of men who go on leave; and, therefore, several go to the same house and frequent the same woman, and then, when he or they have the disease, you can arrive at the name of the woman, who is arrested by the police and lodged in hospital on receiving a letter from the surgeon of the ship detailing the bouse and name. On the sick-list of the Hibernia I found a narine who had been under treatment for twenty days, which consisted in pursuing the recognised plan of giving salines, copaiba, and injections of different strengths and substances, with the usual results in these tedious cases, where th. constitution is beginning to suffer from the long-continued discharge and confinement. This case was really becoming an opprobrium, and we felt anything but satisfied with our treatment. I decided then on trying the permanganate of potash, which I tentatively gare in five grains to the ounce as an injection at least four times a day. This gave rise to no pain or other inconvenience. Since then $I$ have administered it in as many as fifteen grains to the ounce. The resalt in this case was that the man was well in two days, or after about eight injections.

In the course of a fortnight this man went on leave, and came back with a gonorrhca. The same treatment was pursued, with a precisely similar result. I prescribed it also in the case of an officer who had had the disease for six weeks. The discharge in this case was more gleety, and his health was begirning to suffer. On this occasion the cure took sir days, but I do not think he attended fully to the directions I gave him; neither was he regular in its use.

I regret that this is all the evidence $I$ can bring of the good effects of the permanganate; but I see it is needless for me to wait for more cases, so I place this imperfect experiment before the profession. I do not vaunt these cases as being conclusive, because their paucity will hardly warrant me in claiming for this remedy the name of specific; but I bring them forward in order that those who have. more opportunities of treating the disease may be tempted to try the permanganate; and I hope the results will be as satisfactory in their practice as they have been in my three cases. From what I have seen of its action, I feel very sanguine concerning its efficiency. I only ask that those who make use of it will be kind enough to publish their cases, whether attended by success or the reverse.

Now a few words may be necessary as to the method of using the injection. It must be remembered that the permanganate of potash loses its virtue by admixture with any extraneous matter, or exposure; therefore it is advisable to mix the injection immediately before using it. This onght to be done in either a glass or porcelain dish, perfectly free from any greasy matter; and the syringe must be in a like state of purity. If care be not taken in its use the patient's linen will be stained; and this should be remembered in private practice.

I mentioned my cases to some medical friends in the Mediterranean, and requested them to try it, and communicate the results; but I suspect they also suffer from the dearth of cases of which I, pardonably I hope, complain.

While I am writing on this subject it may be mentioned that the infrequency of the disease shows most favourably for the working of the Contagious Diseases Act; and it would be well if this communication could be perused by those whose time is taken up in expressing opinions and flourishing their names in print in connexion with a subject they do not understand, nor ought to know anything about. Until lately I had no idea that "ladies" were so conversant with the diseases resulting from promiscuous intercourse.

Royal Naval Hospital at Haulbowline, Oct. 1870.

\section{UNSUCCESSFUL OVARIOTOMY}

\section{BY W. Y. VEITCH, L.R.C.P. \& L.R.C.S. EDIN.,} SERGEON TO THE NORTH RIDLNG IMFLRMARY.

As we so seldom see recorded unsuccessful operations, and believing that much may be learnt from them, I am induced to forward the following case, which will, I have no doubt, be of use in pointing out what may be expected in what is to all appearances a favourable case for operation.

Mary M- a a the infirmary on the 2 nd of September, 1870 , suffering from abdominal swelling. She first noticed the swelling on the right side six months ago, becoming pregnant about the same time, and aborted four months afterwards. In appearance she was pale, emaciated, and had an anxious expression. The upper lip was unusually hairy ; abdomen distended to the size of a nine-months' gravid uterus, more prominent on the right side, and evidently filled with fluid. Pulse 100, rather weals ; bowels obstinate ; persistent vomiting. Diet: milk, beef-tea, and brandy and soda-water.

Sept. 10th.-Bnwels opened by castor oil and warm-water injections. The sickness still continues. Pulse 120, weak. Tumour increasing in size, and very painful; pain being slightly relieved by hot fomentations and turpentine stupes. I consulted my colleagues on Sept. 12th, the general opinion being that the case was one not without hope of a successful result. It was therefore determined to operate at once. 